\title{
Linfangioma cavernoso retroperitoneal. Presentación de un caso en el Hospital Regional de Alta Especialidad Ciudad Salud
}

\section{Retroperitoneal cavernous lymphangioma. Presentation of a case in the}

\section{Regional Hospital of High Specialty Ciudad Salud}

Lenis A. Zempoaltecatl-Cruz ${ }^{1 *}$, Concepción Cordero-Chaclan², Carmen S. Hernández-Martínez y Federico Arenas-Cruz ${ }^{1}$

${ }^{1}$ Servicio de Radiología; 2 Servicio de Anatomía Patológica. Hospital Regional de Alta Especialidad, Ciudad Salud, Tapachula, Chiapas, México

\section{RESUMEN}

El linfangioma retroperitoneal es un tumor de componente quístico particularmente benigno ocasionado por una malformación congénita. El diagnóstico generalmente se realiza antes de los 3 años, por lo que en los adultos representa un diagnóstico remoto cuando se encuentra a nivel abdominal debido a que por su aspecto y tamaño, en primera instancia, se puede considerar la posibilidad de lesión maligna. Los estudios de imagen tienen un papel radical en la adecuada caracterización de la lesión, teniendo en cuenta los bordes, volumen, composición y reforzamiento en estudios con medio de contraste endovenoso.

Palabras clave: Linfangioma retroperitoneal. Radiología. RM. Adulto.

\section{ABSTRACT}

Retroperitoneal lymphangioma is a particularly benign cystic tumor caused by a congenital malformation. The diagnosis is usually made before the age of 3 years so in adults 
represents a remote diagnosis when it is at the abdominal level because of its appearance and size can be considered the possibility of malignant injury in the first instance. The imaging studies play a radical role in the adequate characterization of the lesion taking into account the edges, volume, composition and reinforcement in studies with intravenous contrast medium.

Key words: Retroperitoneal cystic lymphangioma. Radiology. MRI. Adult.

\section{INTRODUCCIÓN}

Se trata de lesiones benignas raras que son el resultado de una malformación localizada en algún saco principal del sistema linfático. Estas anomalías suelen diagnosticarse clínicamente al nacimiento, y se reporta que aproximadamente hasta en el $90 \%$ antes de los 3 años, por lo que diagnosticarlas en la edad adulta representa un gran reto por la similitud que puede tener con procesos neoplásicos según el sitio donde se localicen ${ }^{1-4}$.

Es importante recordar que el tejido linfático tiene su origen embrionario a partir de sacos linfáticos que derivan del mesodermo. Dichos sacos tienen un orden de aparición consecutivo durante el desarrollo de las estructuras venosas adyacentes a cada uno de ellos, siendo tres sacos los más importantes para establecer un completo drenaje linfático corporal. Los primeros sacos linfáticos que aparecen se localizan en el cuello, justo a nivel de la unión de la vena yugular interna y la vena subclavia, y se extienden posteriormente en forma de capilares adyacentes a venas hacia el tórax, las extremidades y porciones superiores de la cabeza y el cuello. Los segundos sacos linfáticos en aparecer son los retroperitoneales, a nivel de la raíz del mesenterio, que surge a partir de la vena cava primitiva y venas mesonéfricas, las cuales tienen conexión con la cisterna del quilo. Los últimos sacos que se desarrollan son el par posterior, que surge a partir de las venas ilíacas, estos producen plexos capilares y vasos linfáticos de la pared abdominal, pelvis y extremidades. Una vez establecidos, los sacos linfáticos son invadidos por células mesenquimales hacia su porción posterior, y dan origen a los ganglios linfáticos ${ }^{5,6}$.

Las malformaciones del sistema linfático deben catalogarse según la clasificación de la Sociedad para el Estudio de Anomalías Vasculares (ISSVA 2014) en extratronculares y tronculares, para lo cual es necesario valorar mediante diversos métodos de imagen, y de esta manera dirigir un diagnóstico preciso e, incluso, poder sugerir el manejo mediante radiología intervencionista ${ }^{4,5}$.

Se han reportado cuatro formas de presentación de linfangiomas abdominales en relación con su morfología siendo estos ${ }^{7}$ :

- Pediculados, que se diagnostican por torsión.

- Sésiles, frecuentemente localizados entre las hojas del mesenterio.

- Retroperitoneales.

- Multicéntricos, que pueden ser intraperitoneales y extraperitoneales. 
La mayoría de estas malformaciones cursan de forma asintomática y pueden presentarse síntomas únicamente si las dimensiones condicionan efecto de volumen o si presentan alguna complicación, como ruptura, infección o sangrado ${ }^{1-3,6-8}$. Debido a que los linfangiomas se presentan en un amplio rango de edades y de sitios, están asociados con un extenso espectro clínico y de manifestaciones radiológicas 9 .

El diagnóstico de los tumores retroperitoneales se realiza fundamentalmente por estudios de imagen y realizando la correlación respectiva de la exploración física y de estudios de laboratorio ${ }^{10}$.

\section{CASO CLÍNICO}

Paciente mujer de 41 años de edad, soltera, sin antecedentes crónico-degenerativos, que es referida al servicio de admisión continua del Hospital Regional de Alta Especialidad Ciudad Salud por una tumoración abdominal palpable y estreñimiento. A la exploración física se encuentra tumoración sólida, no móvil, no dolorosa en el hemiabdomen izquierdo de aproximadamente $20 \mathrm{~cm}$. No se caracterizan adenopatías en ningún nivel, miembros pélvicos con datos clínicos de insuficiencia venosa crónica. Se realiza una ecografía abdominal en la que se visualiza un tumor retroperitoneal de aspecto heterogéneo, septado con componente quístico, se le realiza tomografía computarizada (TC) abdominal con administración de contraste endovenoso, y se observa una escasa interfase con las estructuras vasculares esplénicas, desplaza las asas intestinales y comprime el colon descendente y el riñón izquierdo, con

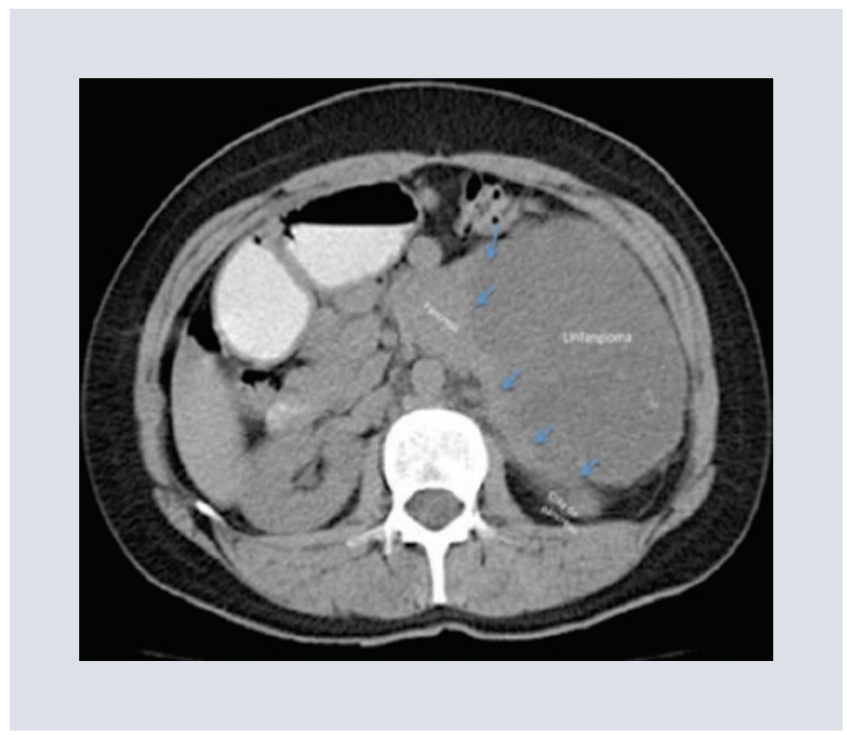

Figura 1. Corte axial de tomografía de fase simple con medio de contraste oral. Se observó un tumor hipodenso, lobulado que contacta con el cuerpo y la cola del páncreas sin delimitar la interfase grasa entre ambos (flechas azules).

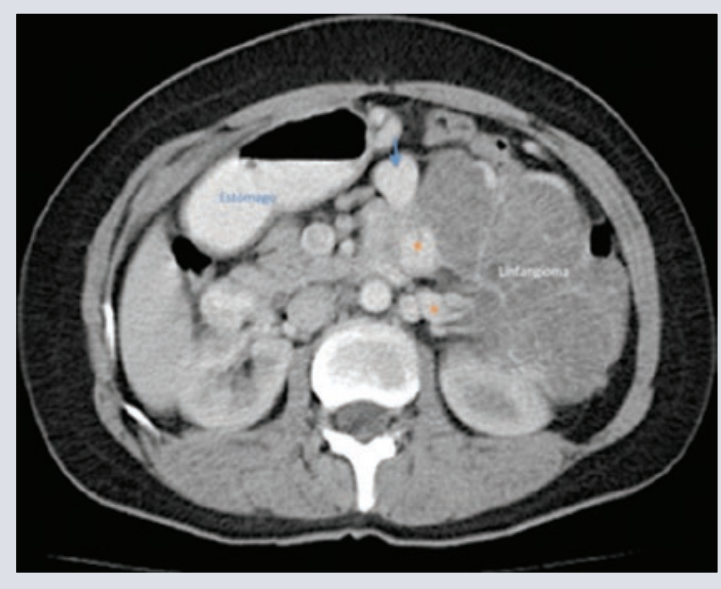

Figura 2. Corte axial de tomografía en fase portal a nivel del hilio renal. Se observa tumor multilobulado que desplaza en sentido caudal el riñón izquierdo, así mismo se observa dilatación de la vena mesentérica (flecha azul) y de la vena esplénica $(*)$.

interfase grasa perirrenal conservada (Figs. 1 y 2). Se caracteriza la lesión mediante resonancia magnética ( $R M)$ y se visualiza un tumor quístico, lobulado, de intensidad heterogénea, con hiperintensidad en las secuencias sensibles a T2, de componente quístico multiloculado con septos que presentan 


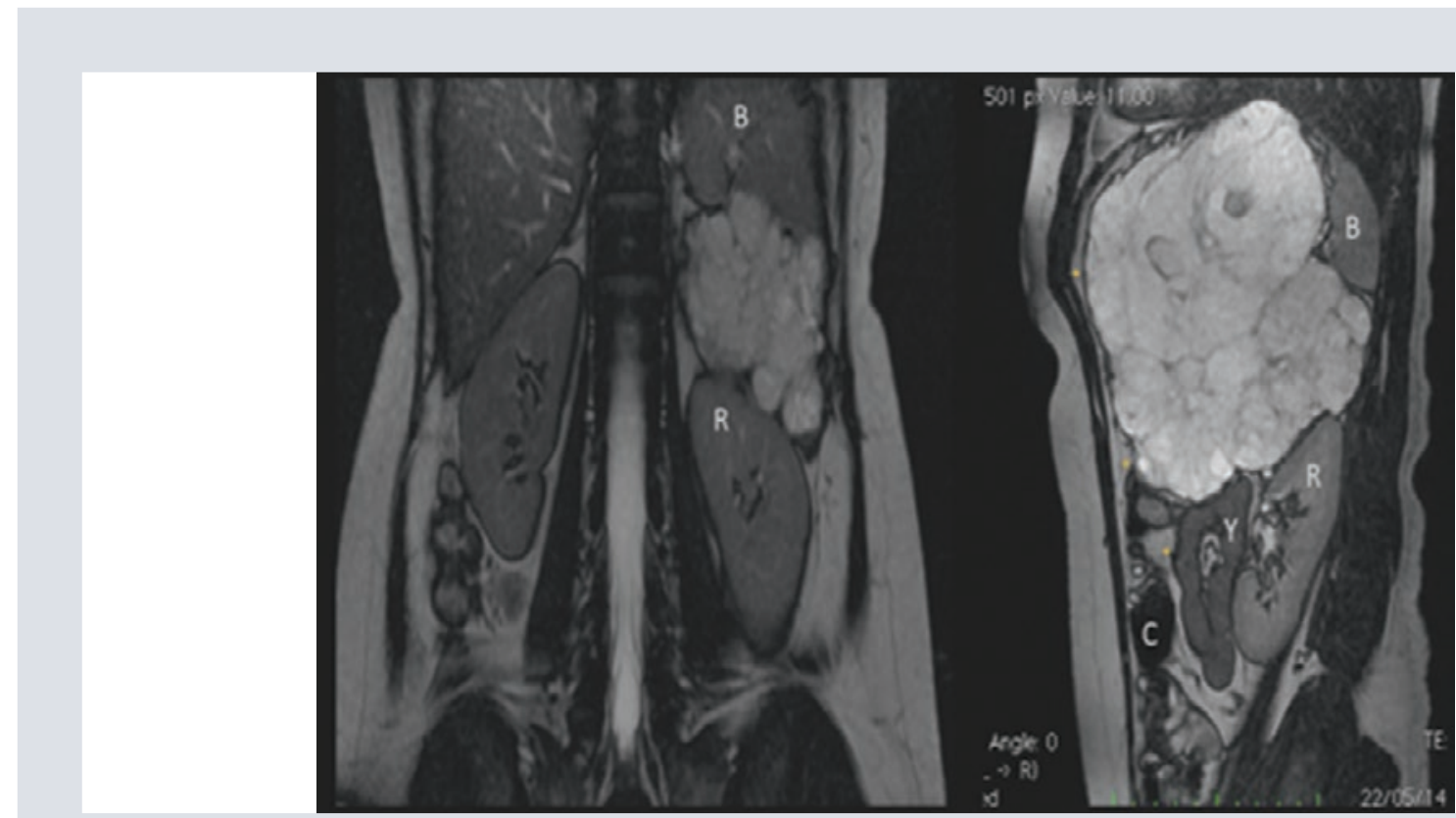

FIGURA 3. Imágenes de resonancia magnética en secuencias 2D FIESTA, plano coronal y sagital. Se demuestra la interfase que existe entre el tumor multiquístico con el riñón (R) y con el bazo (B).

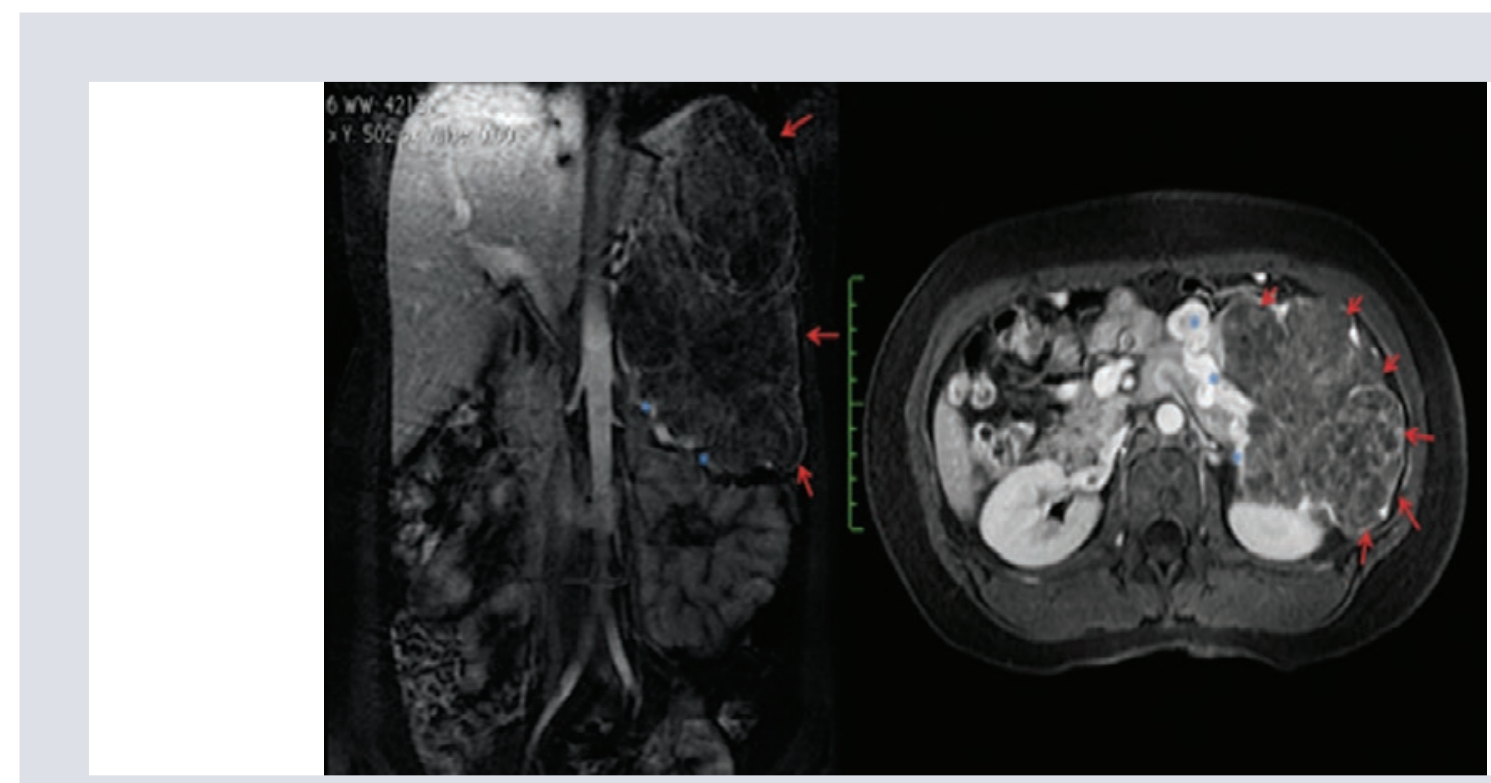

Figura 4. Imágenes de resonancia magnética en secuencia T1 con supresión grasa y administración de gadolinio en el plano coronal y axial. Se muestra un tumor quístico lobulado con reforzamiento capsular (flechas rojas), se delimitan septos y contenido quístico franco. Vena esplénica y mesentérica dilatadas y tortuosas $(*)$.

reforzamiento bajo heterogéneo y que condiciona el desplazamiento de las estructuras adyacentes sin infiltrarlas (Figs. 3 y 4 ).
Se realizó laparotomía exploradora y se efectuó resección completa del tumor: se encontró un tumor sólido encapsulado. En 
TABLA 1. Hallazgo radiológicos de linfangioma abdominal por diferentes métodos

\begin{tabular}{|c|c|c|c|}
\hline Radiografía simple de abdomen & Ultrasonido & Tomografía & Resonancia magnética \\
\hline $\begin{array}{l}\text { Aumento focal de la radio opacidad } \\
\text { Desplazamiento de estructuras } \\
\text { retroperitoneales } \\
\text { Alteración del patrón de distribución } \\
\text { de gas intestinal endoluminal } \\
\text { Elevación del hemidiafragma } \\
\text { Borramiento del psoas }\end{array}$ & $\begin{array}{l}\text { Caracteriza las porciones quísticas, } \\
\text { aspecto y grosor de los septos y la } \\
\text { vascularidad utilizando la } \\
\text { modalidad Doppler color } \\
\text { Pueden observarse detritus } \\
\text { ecogénicos móviles }\end{array}$ & $\begin{array}{l}\text { Define la localización del tumor, } \\
\text { compromiso vascular } \\
\text { Permite delimitar la densidad } \\
\text { de las porciones quísticas } \\
\text { Define el reforzamiento y } \\
\text { delimita la interfase con } \\
\text { estructuras libres de lesión }\end{array}$ & $\begin{array}{l}\text { Define de forma adecuada las } \\
\text { interfases con tejido libre de } \\
\text { lesión, delimita el compromiso } \\
\text { vascular } \\
\text { Caracteriza las porciones } \\
\text { quísticas }\end{array}$ \\
\hline
\end{tabular}

la valoración por el servicio de anatomopatología, se ve una tumoración con superficie externa lobulada. Al corte, la superficie interna muestra áreas quísticas de diferente tamaño, con presencia de tejido hemático y líquido de color café (Fig. 5). Se realizó revisión de las laminillas con tinción de hematoxilina y eosina y se encontró una lesión constituida por espacios linfáticos de diferentes tamaños, dilatados, revestidos por células endoteliales, con presencia de material linfático y hemático (Fig. 6).

Se concluyó seguimiento de la paciente por parte de consulta externa, con mejoría franca de la sintomatología.

\section{DISCUSIÓN}

Los linfangiomas retroperitoneales son malformaciones generalmente complejas de baja incidencia. Mediante los diversos métodos de imagen muestran un comportamiento característico condicionado por sus componentes. En ultrasonido se encuentran frecuentemente como quistes gigantes multiloculados, y mediante tomografía se visualizan tumores poliquísticos con múltiples septos delgados, con variación en su densidad entre cada quiste (Tabla 1) ${ }^{1-3,8-11}$. La mayoría de los linfangiomas retroperitoneales son asintomáticos y los

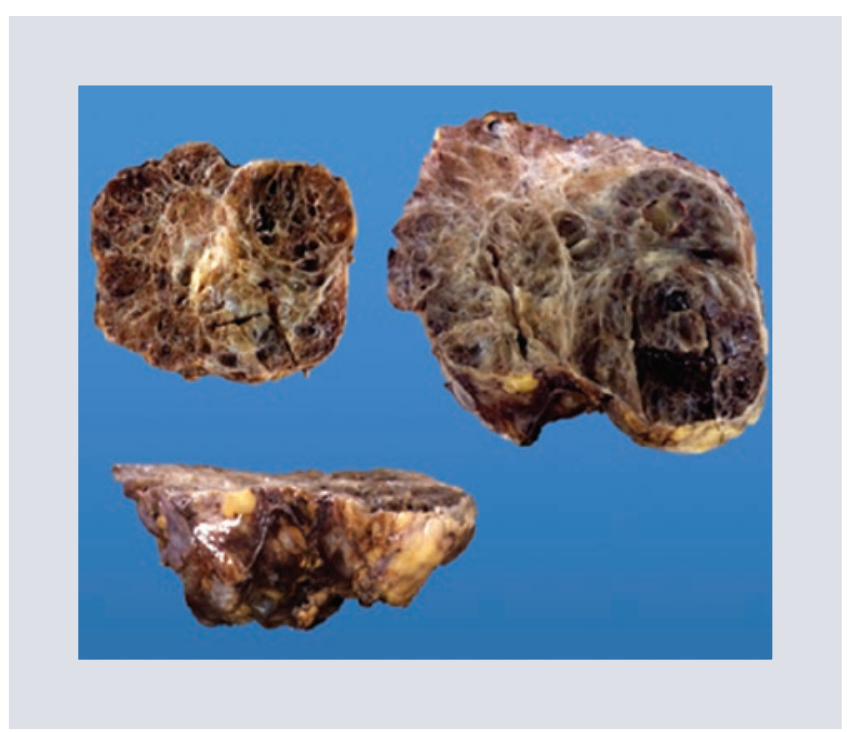

Figura 5. Tumoración con superficie externa lobulada. Al corte, la superficie interna muestra áreas quísticas de diferente tamaño, con presencia de tejido hemático y liquido de color café.

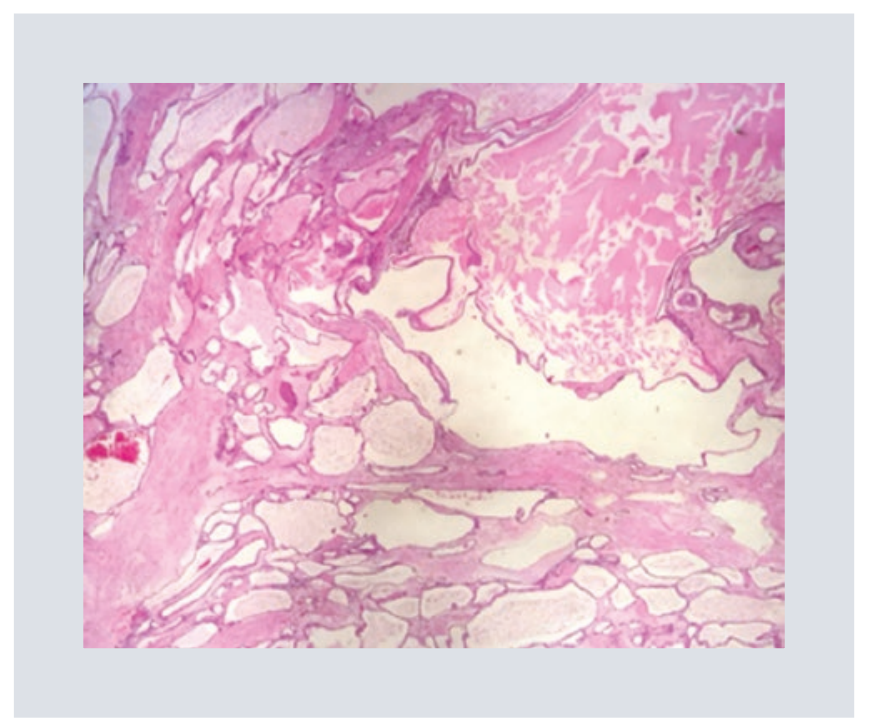

Figura 6. Laminilla con tinción de hematoxilinia-eosina. Lesión constituida por espacios linfáticos de diferentes tamaños, dilatados, revestidos por células endoteliales, y con presencia de material linfático y hemático. 
síntomas dependen de sus dimensiones y de las estructuras anatómicas circundantes ${ }^{7}$.

Típicamente no se limitan a un compartimento y suelen, por su gran tamaño, desplazar y comprimir estructuras anatómicas adyacentes ${ }^{10-14}$.

El retroperitoneo es una de las áreas más complejas de la anatomía humana, al situarse en este espacio una gran variedad de órganos y estructuras pertenecientes a diferentes sistemas, especialmente el aparato urinario, digestivo y vascular. La incorporación de distintas técnicas diagnósticas de imagen nos ha permitido estudiar al detalle el retroperitoneo, por lo que gracias al ultrasonido, la TC y la RM se ha logrado un avance significativo en la valoración de múltiples patologías que afectan a este sitio anatómico, y han hecho que se logre establecer de forma más confiable las características y relaciones anatómicas implicadas al momento de estudiarse alguna patología ${ }^{11}$.

Los diversos métodos de imagen tienen un papel importante en la adecuada caracterización de la lesión, el ultrasonido es útil cuando el defecto se encuentra en los tejidos blandos superficiales y que dependan de la cara, el cuello o las extremidades, también este método es útil en el diagnóstico de forma prenatal. En el caso de los linfangiomas retroperitoneales de gran tamaño, el ultrasonido es una herramienta con limitaciones y con un sesgo condicionado por tratarse de un estudio dependiente del operador ${ }^{10,13-14}$. La TC y la RM brindan un mejor detalle anatómico, así como una mejor aproximación en cuanto a las dimensiones y órganos asociados, guían sobre las estructuras vasculares comprometidas y sirven como apoyo para una adecuada planeación quirúrgica, también pueden utilizarse como estudios de control ${ }^{10}$.

Los diagnósticos diferenciales incluyen lesiones benignas, como quistes del urotelio, quistes de intestino anterior, microquistes pancreáticos, hematomas retroperitoneales, abscesos, quistes de duplicación intestinal, quistes ováricos, pseudoquistes pancreáticos, tumores malignos, como mesotelioma quístico, teratoma quístico, sarcoma, metástasis quísticas de origen ovárico o gástrico, linfangiosarcoma e incluso osteoliposarcoma ${ }^{7}$.

En nuestro caso se encontró que la TC no excluyó de forma precisa las interfases de las estructuras anatómicas regionales, por lo que se recurrió a la RM, con lo que se logró delimitar la adecuada interfase con el bazo y el páncreas.

El tratamiento consiste en la resección quirúrgica abierta o mediante cirugía laparoscópica, en casos especiales en donde la resección no es posible se puede considerar escleroterapia; sin embargo, si no es posible caracterizar el compromiso vascular, se sugiere la visualización directa de la lesión.

\section{CONCLUSIÓN}

El papel del radiólogo en el diagnóstico de tumores retroperitoneales es fundamental, ya que la adecuada discriminación del comportamiento entre lesiones de tipo benigno o maligno permite sugerir un adecuado abordaje. Es fundamental tener en cuenta que se requiere del diagnóstico histopatológico para sugerir el seguimiento radiológico del paciente sin hacer sobreuso de los diversos métodos de imagen, en especial de la TC. 


\section{CONFLICTO DE INTERESES}

Los autores declaran no tener ningún conflicto de intereses.

\section{FINANCIAMIENTO}

Los autores declaran que no recibieron financiación para este estudio.

\section{RESPONSABILIDADES ÉTICAS}

Protección de personas y animales. Los autores declaran que para esta investigación no se han realizado experimentos en seres humanos ni en animales.

Confidencialidad de los datos. Los autores declaran que han seguido los protocolos de su centro de trabajo sobre la publicación de datos de pacientes.

\section{Derecho a la privacidad y consentimiento} informado. Los autores han obtenido el consentimiento informado de los pacientes y/o sujetos referidos en el artículo. Este documento obra en poder del autor de correspondencia.

\section{BIBLIOGRAFÍA}

1. Beltrán MA, Barria C, Pujado B, Oliva J, Contreras MA, Wilson CS, et al. Linfangioma esplénico gigante: caso clínico. Rev Med Chile. 2009;137(12):1597-1601.

2. Yang F, Chen WX. Splenic lymphangioma that manifested as a solid-cystic mass: A case report. World J Gastroenterol. 2013;19(5):781-3.

3. Chang WC, Liou CH, Kao HW, Hsu CC, Chen C.Y., Yu C.Y.. Solitary lymphangioma of the spleen: Dynamic MR findings with pathological correlation. Br J Radiol. 2007;80(949):e4-e6.

4. Correia FM, Seabra B, Rego A, Duarte R, Miranda J. Cystic lymphangioma of the mediastinum. J Bras Pneumol. 2008;34:994-6.

5. Gross RE. Cystic hygroma. En: The surgery of infancy and childhood. Philadelphia: WB Saunders; 1953. p. 960-70.

6. Levine C. Primary disorders of the lymphatic vessels. A unified concept. J Pediatr Surg. 1989;24:233.

7. Gayen R, Mahata M, Dasgupta S, Dasgupta J. Giant retroperitoneal cystic lymphangioma - a case report with review of literature. IOSR J Dental Med Sci. 2015;14:69-71.

8. Yang DM, Jung DH, Kim H, Kang JH, Kim SH, Kim JH, et al. Retroperitoneal cystic masses: CT, clinical, and pathologic findings and literature review. Radiographics. 2004;24:1353-65.

9. Levy AD, Cantisani V, Miettinen M. Abdominal lymphangiomas: imaging features with pathologic correlation. Am J Roentgenol. 2004;182:1485-91.

10. Merran S, Karila-Cohen P, Vieillefond A. Primary retroperitoneal tumors in adults. J Radiol. 2004;85(2 Pt 2):252-64.

11. Zuluaga Gómez A, Jiménez Verdejo A. Patología retroperitoneal. Actas Urol Esp. 2002;26(7):445-66.

12. Alapont Alacreu JM, Arlandis Guzmán S, Burgués Gasión JP, GómezFerrer A, Jiménez Cruz JF. Tumores retroperitoneales primarios: nuestra casuística. Actas Urol Esp. 2002;26(1):29-35.

13. Kutta A, Engelmann U, Schmidt U, Senge T. Primary retroperitoneal tumors. Urol Int. 1992;48(3):353-7.

14. Gómez Pascual JA, Martín Morales A, Bonilla Parrilla R,Alvarado Rodríguez A, Blanco Reina F, Rodero García P, et al. Linfangioma quístico retroperitoneal. Una patología silente en adultos. Actas Urol Esp. 2002; 26(5):356-60. 